April - 2002

\title{
Electronic Tutorials: Indonesian experience
}

\author{
Tian Belawati, Mohamad Toha Anggoro, A.P. Hardhono, and Tri Darmayanti \\ Universitas Terbuka \\ Indonesia
}

\begin{abstract}
As in other developing nations, important concerns surrounding education in Indonesia involve two issues: quantity versus quality. Quality concerns have now been somewhat addressed by the establishment of the Indonesian Open Learning University (Universitas Terbuka) in 1984. The concern for quality, however, has not yet been completely resolved. Learning support, believed to be key for achieving good quality distance education, has been limited. This paper presents the results of two pilot projects that examined tutorials provided via Internet and Fax-Internet technologies. It is a report that also shows that the Universitas Terbuka is faced with both visible and invisible challenges. Visible challenges include limitations in the availability of technology infrastructure and issues of inadequate access, while invisible challenges include the readiness of Indonesian people to adopt and take advantage of new technology for educational purposes. Despite the results of the pilot project, it is suggested that Universitas Terbuka should continue to utilize Internet and Fax-Internet as two of its communication channels with students.
\end{abstract}

Keywords: Electronic tutorials; Fax-internet tutorials; Indonesian distance learning; Internet tutorials; Internet; Indonesia

\section{Background}

Entering the new millennium is both exciting and intimidating for countries such as Indonesia. The general consensus is that Indonesia has entered the information age, and that the country will not be exempt from the current forces of technological development and globalization (Taylor, 1998). Clearly, the impact of the information age has raised many worries and challenges. The analogy that best describes the situation is that "while Indonesians are still struggling with malnutrition, they are also facing heart disease as the number one killer."

Indonesia has been facing a multi-facet crisis since mid 1997, beginning with its monetary and economic crisis. With economic, political, and social stabilization at stake, other social sectors including education - are often seen as a low priority. The indefinite cancellation of educational programs is clear evidence of this current trend.

Today the most important concerns in education in Indonesia (as in many other developing nations) involve two issues: quantity versus quality. Quantity of education refers to the coverage of educational provisions, namely: How many people have access to education? How many schools are available? Who has access to education? To a degree these concerns have been 
addressed by the establishment the Universitas Terbuka in 1984, an initiative that has increased public access to higher education, especially for those who cannot engage in study due to demographic, economic, time or space barriers. Operating for 14 years, Universitas Terbuka has served more than 400,000 students throughout the country, a statistic that reflects a national participation rate of approximately 12 percent of the total student population currently attending Indonesia's 200 plus higher education institutions.

Quality concerns have not yet been completely resolved. Despite its success in terms of increasing student access (quantity), the quality of Universitas Terbuka's educational programs and initiatives are perceived as questionable. Can Universitas Terbuka, which employs distance education method of instruction, deliver the same quality of education as "good teachers" in the classroom? Can interactions between teachers and students be accommodated? Can distance delivery provide adequate feedback to students? Indeed, like many other distance education institutions, Universitas Terbuka relies on traditional printed course materials and to a lesser degree broadcast media like radio. The University also provides limited student access to newer technologies such as telephone, videocassettes and computers. In short, Universitas Terbuka is struggling to address questions surrounding quality. To date, the main learning medium used by the University has been print-based materials supplemented by radio and to a lesser extent video and television broadcast programming. In other words, learning support, believed by many to be key for achieving good quality distance education, has been limited.

Universitas Terbuka has nonetheless strived to employ different tutorial models to enhance and facilitate student support. These models include face-to-face and distance tutorials delivered via regular mail, radio, television, and more recently via Internet and Fax-Internet technologies. Tutorial models using Internet and Fax-Internet are still at their introductory stage at the University. This article will focus on the outcomes of two pilot tutorial projects undertaken by Universitas Terbuka: The first pilot solely using the Internet as its communication channel with students, and a second pilot using a less expensive combination of Fax-Internet technologies.

\section{The Design of Tutorials Using Internet and Fax-Internet Technologies}

\section{Internet Tutorials}

Since the establishment in 1997 of the national electronic communication infrastructure called "Nusantara-21," the Internet has been seen by many in Indonesia to be a promising information and communication medium. An experimental study conducted to test the feasibility of counseling at a distance via the Internet showed the Internet to be an effective medium for communicating with students (Belawati, 1998). Despite concerns surrounding high access costs and low computer literary among students, those who participated in the study expressed satisfaction of having being able to communicate directly with Universitas Terbuka's counselors.

Intended for affluent students who live in relatively urban areas and can afford the necessary costs, but who are too busy to attend rigidly scheduled face-to-face tutorials, this tutorial model is seen as a feasible alternative. Internet facilities are now available for public use in many telecommunication kiosks (known as Wartels), located in Indonesia's cities. Rental costs for accessing public Internet services in Wartels are also relatively affordable, especially when it shared among several students. For example, when shared by ten students, the cost for Internet access per student is about Rp. 3.500 (50 cents US per month). 
Tutorials delivered via the Internet (i.e., tutorials via emailing-lists), are similar to face-to-face tutorials. This method allows students to interact with both their tutors and peers. But unlike faceto-face tutorials, these interactions are asynchronous and feedback between student and tutors is delayed (Toha et al., 1999). The strength of Internet tutorials lies, however, in its ability to overcome scheduling conflicts usually inherent in face-to-face tutorial settings. Since student/ tutor interactions are not conducted in real time, students can post questions, raise issues, and read tutors or other students' responses at their convenience. Similarly, tutors have increased flexibility in terms of scheduling their tutorials, preparing materials, and responding to students' questions.

The tutorials are designed to employ Internet email applications. Every course has a private email list. Four types of email lists are available: 1) open and non-moderated; 2) open but moderated; 3) closed and non-moderated; and 4) closed and moderated. Based on the rationale that tutorials are exclusively provided for Universitas Terbuka's students, the model chosen for the pilot was the closed and moderated email list (see Figure 1).

Figure 1. Communication within tutorials via the Internet

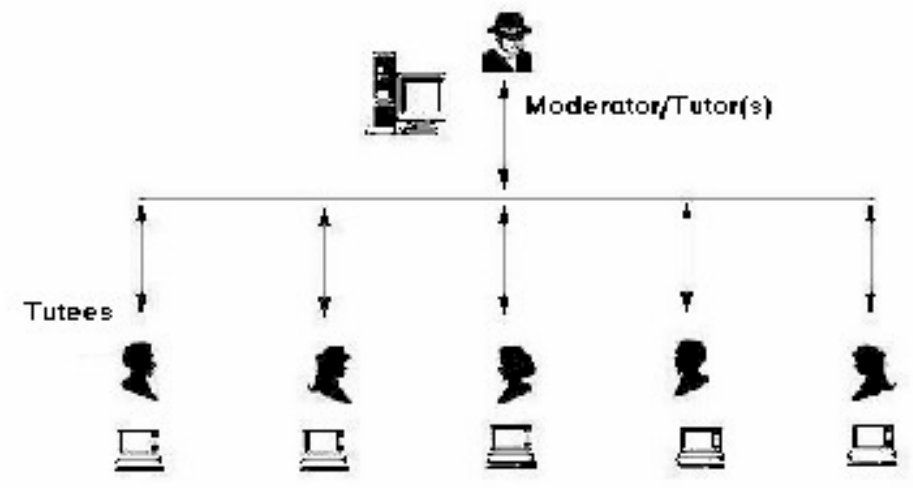

Each course was tutored by one or more tutors and assigned a separate group email list, which was subsequently moderated by the tutor coordinator. Tutors were responsible for preparing materials for at least five student contacts using email as their mode of communication. Put simply, email would be used to initiate, maintain, and facilitate student interaction. Emailed materials were in the form of course and textbook summaries, exercises, or questions. To ensure tutors adequately maintained the tutorials, they are obliged to:

- Initiate at least five student contacts

- Check their email at least once every three days

- Respond to any email received from students within 72 hours

- Make arrangements for his/ her replacement in case of absence (i.e., three days of more)

- Monitor and evaluate the tutorial activities

- Write a resume of tutorial contents (including the most frequently asked questions) at the end of the semester 


\section{Fax-Internet Tutorials}

Many students attending Universitas Terbuka work in low-income jobs. Although low-cost public Internet access is readily available in Indonesia, many students still find Internet access to be prohibitively costly. To overcome this barrier to education, the University has developed an alternative delivery model that combines Internet with less expensive facsimile technology, a strategy that lowers costs while expanding the University's Internet tutorial system to reach less advantaged students. The only difference between the two systems rests in the students' point of access: Internet using email versus a less expensive combination of facsimile and Internet email.

Within the design of Internet tutorials, students were required to have Internet access and basic computer skills (i.e., opening and sending email). Conversely, students participating in the combination Fax-Internet tutorials were required only to have access to a fax machine, older but reliable technology that is widely available for public use in Indonesia's telecommunication Wartels. When communicating via fax, students do not require basic computer skills to participate (Hardhono \& Belawati, 1998).

The cost for sending and receiving faxes range from Rp. 1000 to Rp. 5000 (about 60 cents US), depending on the destination and applicable long distance charges. With the convergence of facsimile with Internet technologies, students no longer send their faxes to another fax machine. Instead, students send their faxes through the closest "fax gateway" installed in the University's regional offices, a system that transmits students' faxes to tutors' email systems. In turn, messages from tutors are sent through the Internet as email and received as faxes by students, a process that lowers the barriers to education associated with low computer literacy and purchasing Internet access. Fax-Internet technology also lowers Universitas Terbuka's operational expenses. Figure 2 depicts the communication design of tutorials through Fax-Internet media.

Figure 2. Communication within tutorials using Fax-Internet technology

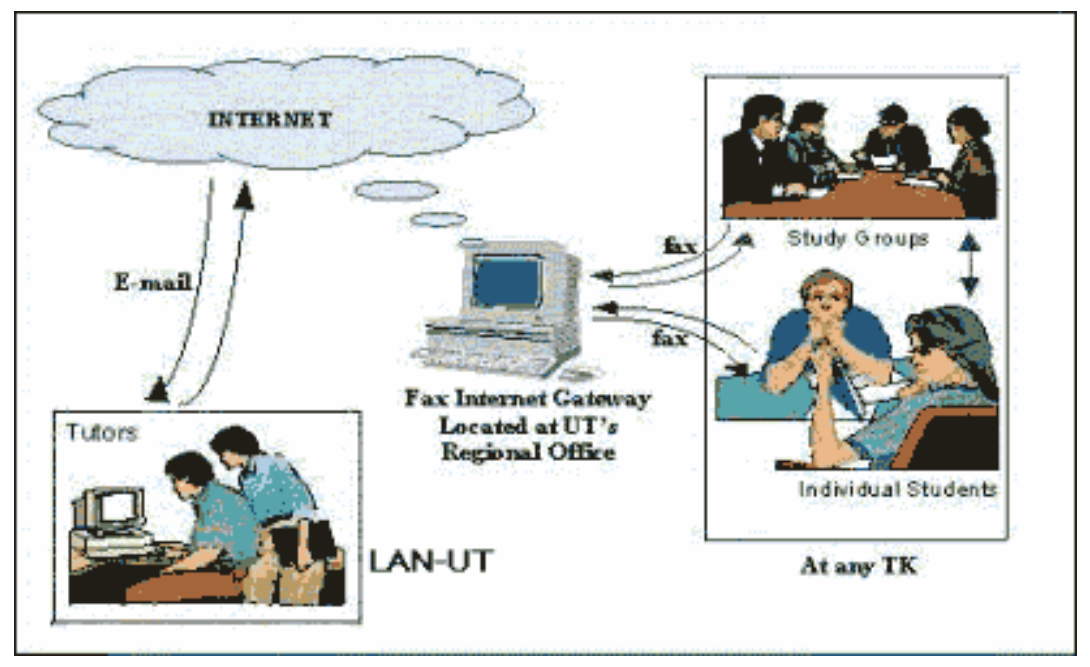




\section{The Implementation of Tutorials Through Internet and Fax-Internet}

\section{Preparation}

Tutorials are currently designed for 40 courses. Selected by individual faculties, these courses are based on their level of difficulty as determined from low examination scores. Once the courses and the tutors were selected, they attended a two day long training session that focused on such skills as:

- Familiarization of the email software (Pegasus mail)

- Email management techniques for each email list, specific to each course

- Development of learning materials for contact initiation

- Technical skills, such as posting and responding to questions using email

While tutors were busy preparing their tutorial materials, the new tutorial model was marketed to students using promotional emails sent to approximately 400 students identified as having previously sent email to the Universitas Terbuka website. Leaflets outlining the tutorial courses were also distributed through all Universitas Terbuka's thirty-one regional offices. As well, faceto-face presentations were also held at the University's regional offices. Data gathered from a questionnaire showed that 38.5 percent of the students enrolled in the tutorials received promotional information via email; 23 percent received promotional information from the University’s website; and only 7.8 percent from such sources as leaflets and oral presentations.

\section{Student Participation Rate}

\section{Tutorials via the Internet}

Student participation can be analyzed on two levels: first, the number of students enrolled in each course; and second the frequency of interaction (contact) between students and tutors during the tutorial sessions. Of the 40 courses available to students, Universitas Terbuka's Marketing Management I course had the highest enrollment numbers. Figure 3 shows student enrollment numbers for each course that used the Internet tutorials.

Figure 3. Student enrollment rate per course 


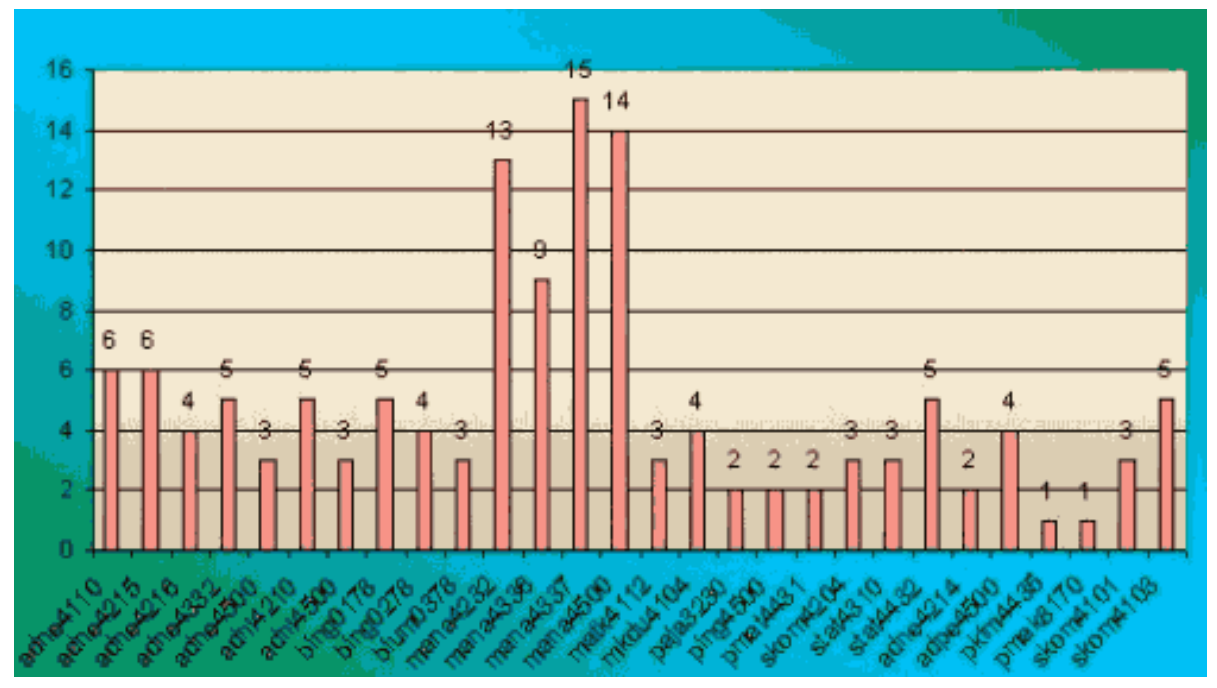

Students enrolled in SKOM 4103 (Introduction to Public Relations) were the most active. While only five students subscribed to this course, the frequency of contact was far higher than that of students enrolled in any other course. Figure 4 shows the student/ tutor interaction rate of each course during the pilot project. Figure 4 also shows that in some courses no interaction occurred between tutees or tutors. This is interesting, given that tutors were required to send emails to at least five initial student contacts.

Figure 4. Student/ Tutor interaction rates per course

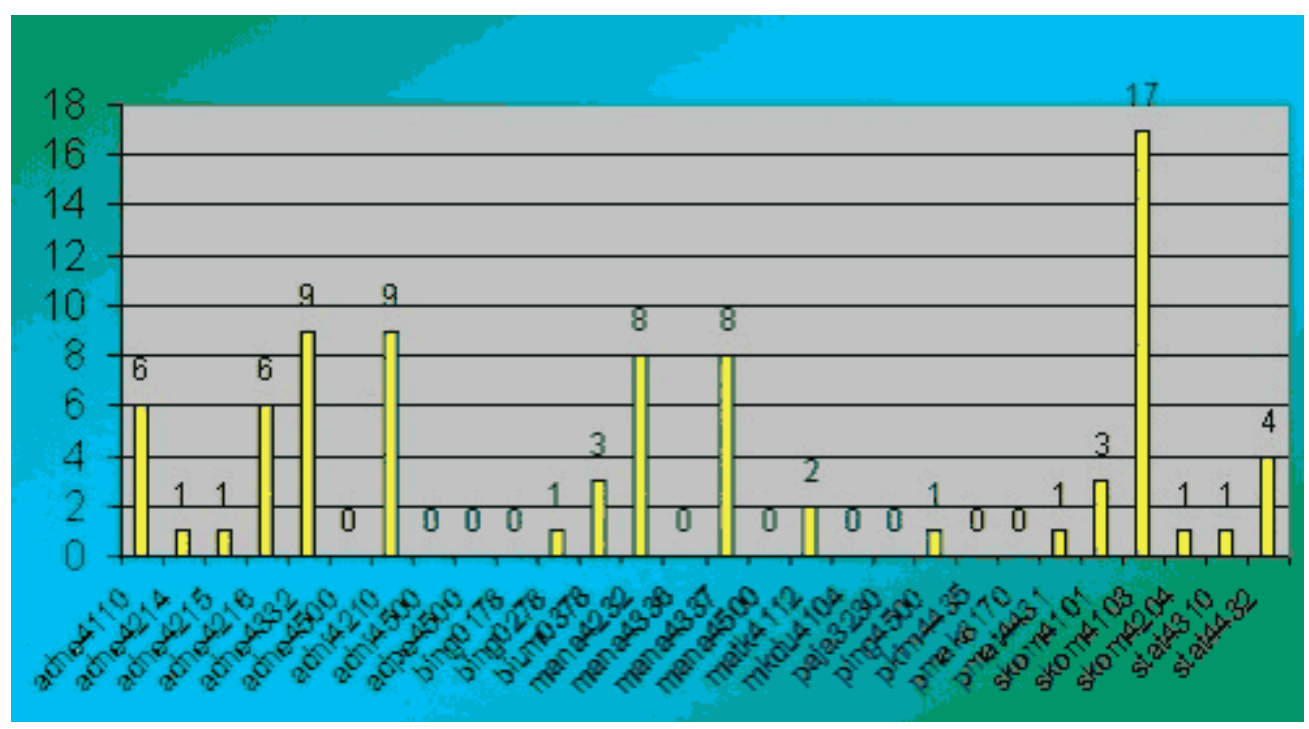

Even though this data appears to be discouraging, other sources of data show that tutors nonetheless received email from their students albeit through alternative addresses such as the Center for Student Services (pelma@p2m.ut.ac.id) and the Information Unit (info@p2m.ut.ac.id). For example, the tutors of ADNE 4500 (Written Comprehension Examination) received 15 
emails via these two alternative email addresses; however, they were not recorded by the pilot project's email log. This supplementary information could be interpreted to mean that the actual electronic interaction between students and tutors was much higher than shown in Figure 4. However, this finding also suggests that the electronic tutorial introductory sessions need to be redesigned and intensified in the future.

The electronically recorded student participation rates in the tutorials were also supported by the data gathered through the questionnaire. Thirty eight percent of the 13 students who responded to the questionnaire admitted that they never sent email, and among those who did, the number of email sent was low with only about one or two emails sent during the entire two-semester long pilot project. In sum, the total number of email transactions recorded during the pilot project was 82, while data collected from 13 returned questionnaires show that 54 percent of the students had received or sent at least one email.

With regard to the low student participation rate: 1) Forty-three percent of students questioned mentioned that their lack of confidence with email subsequently resulted in their not adequately understanding course materials. 2) Fourteen percent admitted to confusion about how to send email. 3) Twenty percent felt that the tutorials were irrelevant. 4) Fourteen percent claimed that they did not know their tutors' email addresses. The second and the fourth reasons listed above indicate that for electronic tutorials to be successful, students need to be trained how to use email and emailing lists, particularly on how to send and retrieve email. The other two reasons indicate that students still do not understand the purpose of tutorials, which ironically is to help them comprehend the course materials being tutored. Misunderstanding about the purpose of tutorials was also revealed by the nature and content of students' questions. Only 35 percent of the questions received from students directly related to course materials, whereas the majority of questions concerned administrative issues.

\section{Tutorials through Fax-Internet}

Unlike the tutorials through Internet, which can be accessed by students throughout Indonesia, tutorials through Fax-Internet is only available for students within the University's Fax-Internet Gateway (FIG) service area. Due to resource limitations, the FIG is currently only located in seven (out of 31) of Universitas Terbuka's regional offices: Bandung, Bogor, Jakarta, Jayapura, Pontianak, Purwokerto, and Surabaya.

Student participation rate in these tutorials was low: only 20 student-sent faxes were received during the two semester-long pilot project, nine of which involved strictly administrative matters. However, each fax contained between one and nine questions. Table 1 shows the number of faxes and questions received per course. As shown in Table 1, few students took advantage of the FaxInternet technology as their communication medium. This is interesting, because it was assumed that those who had enrolled in these courses desired this form of tutorial as a lower-cost alternative to Internet tutorials. One possible explanation for low student participation was that promotions for Fax-Internet tutorials and Internet tutorial were conducted as one package. In short, it appears that the students were not aware of the distinctions and differences between the two communication channels. The leaflet and the emails sent to students were perceived as a singular promotion for Internet tutorials only.

Table 1. Number of Faxes received per course 


\begin{tabular}{|l|c|c|c|c|c|c|c|}
\hline \multirow{2}{*}{ Course } & Number of & \multicolumn{6}{|l|}{ Number of Questions Asked } \\
& $\begin{array}{l}\text { Faxes } \\
\text { Received }\end{array}$ & $\mathbf{1}$ & $\mathbf{2}$ & $\mathbf{3}$ & $\mathbf{4}$ & $\mathbf{6}$ & $\mathbf{9}$ \\
\cline { 4 - 8 } & 2 & & 2 & & & & \\
\hline ADNE4215 & 1 & & $\mathbf{1}$ & & & & \\
\hline ADNI4110 & 1 & & & & & & 1 \\
\hline ADNI4500 & 3 & 1 & & & 2 & & \\
\hline EKON4112 & 1 & & & & & 1 & \\
\hline MANA4110 & 1 & & & & 1 & & \\
\hline MANA4232 & 1 & & & 1 & & & \\
\hline MKDU4104 & 1 & & 1 & & & & \\
\hline MKDU4107 & 1 & & & & & \\
\hline
\end{tabular}

Table 1. Number of Faxes Received Per Course

\section{Tutor Responsiveness Rate}

\section{Tutorials via the Internet}

Tutor responsiveness to incoming email was likewise disappointing. Even though tutors initially agreed to adhere to minimum performance guidelines, they failed to do so (i.e., tutors were to initiate contact with students, check their email at least once every three days, and respond within 72 hours to any incoming email, etc.). As a result, a test-email was sent to tutors to determine their overall responsiveness to email. This test-email revealed that only 19 out of the 98 tutors (19 percent) involved in the pilot project checked and opened their email (sent as a test case) within five days; and 80 tutors (81 percent) did not even open their email account until after the report was written. Furthermore, only 27 percent of tutors, as they had agreed prior to the launch of the pilot project, wrote a resume and a FAQ of the tutorials at the end of the semester.

\section{Tutorials through Fax-Internet}

Similar to the experiences of Internet tutorials, tutors were not overly responsive to students' questions sent via fax. The University's electronic records indicated that of the 20 faxes received during the pilot phase, only one student received response from their tutor. This, however, does not necessarily mean that students receive no response at all. When asked, tutors claimed that they responded to students' questions via fax - not email. This finding indicates that tutors did not entirely understand the purpose of using the FIG - i.e., reducing the University's costs related to long-distance charges using fax technology.

The above data clearly show that the tutors failed to demonstrate a high-level of commitment towards their tutorial responsibilities. Tutors often cited limited availability of computers and time constraints as reasons for not adhering to their new tutorial responsibilities. Although these explanations could be accepted to some extent, conducting tutorials nonetheless remain one of their main responsibilities as academic staff. This situation suggests that the University's academic staff need to be retrained, although admittedly the availability of computers needs to be increased as well. It has been determined that at the ideal tutor to computer ratio to support electronic tutorials is 1:5; whereas at Universitas Terbuka, the current tutor to computer ratio is $1: 20$.

\section{Factors Related to the Success of Tutorials}

Aside from the apparently low commitment on behalf of the tutors, other factors stemming from technical and non-technical difficulties also hampered the overall performance of the electronic tutorials. Technical difficulties such as mistakes in writing down email addresses, use of free 
email for accessing the tutorials, and mistakes in registering (subscribing) to course emailinglists, were commonly cited.

Within the emailing-list application, email was supposed to be sent to a given email- list address as identified by a requisite course code (e.g., ADNE4335 is the email-list for the course ADNE 4335). In this manner, all emails would be emailed to the same account, which was to be moderated by a tutor. However, many students held the mistaken belief that these email-lists were not a group-list per say, but one-to-one communication. As a result, students often mistakenly sent their email directly to individual's using their personal email addresses, thereby bypassing the group discussion emailing-list system altogether. This, of course, created a condition in which some of the emails remained unmonitored and worse required the moderator to response to individual questions, rather than the tutorial group as a whole.

Problems caused by free email facilities, popular with many students, was also a factor that was unanticipated by the manager of the email server. Email sent from free email providers such as Hotmail, could not be processed by the University's email server. Therefore, such email had to be manually forwarded, requiring extra expense in terms of staff time and effort.

Lastly, typing mistakes were often made by students during their attempts to subscribe to the group tutorials. The electronic mechanism does not tolerate mistyping. The design for subscribing was: Subscribe CODEXXX with no space between the "CODE" and the number "XXX" - e.g., Subscribe ADNE4335. Therefore, if a student typed "Subscribe ADNE 4335" with a space between the letters and numbers, the registration could not be processed; hence the student was not able to participate in the tutorials.

Combined with the tutors' previously mentioned defenses (i.e., limited availability of computers and time constraints), tutors also said that low student participation and interaction had a dampening effect on their overall motivation. Many tutors claimed this was why they did not regularly check their email lists as originally agreed. In cases where tutorials were handled by a team comprising of more than one tutor, the organization and setting-up of team meetings were said to be next to impossible. Interestingly, these same tutors did not think to use their own email systems to help conduct asynchronous meetings. This demonstrates that the tutors were not yet comfortable using email as a means of communicating amongst themselves, let alone with their students. Low tutor participation can also be seen from a different angle, such as the need for Universitas Terbuka to redesign its policies to support the implementation of this tutorial form. There are also some aspects of day-to-day management related to the success of Internet tutorials that should be highlighted. First, the current workload of tutors is presently dominated by lowlevel administrative tasks often performed at the expense of their academic responsibilities. Therefore, it seems advisable that the University should contemplate redefinition of its tutorial staffs' job descriptions. Likewise, there is no official policy at faculty level that encourages tutors to learn and optimize their tutorial teaching activities via the Internet.

\section{Conclusion}

Tutorials are an integral part of distance education, a fact that is well understood by Universitas Terbuka as evidenced by its ongoing effort to provide tutorial sessions using different media. Electronic tutorials conducted through Internet and Fax-Internet technologies are simply the latest tutorial delivery model that has been piloted. The survey conducted prior to the pilot project revealed that the Indonesian electronic communication infrastructure has expanded sufficiently to support increased student access through the use of Internet and Fax-Internet technology. Data 
also show that the combination of Internet/ Fax access available through Wartels cost less and is thus more affordable for Universitas Terbuka's poorer students. However, implementation of these two electronic tutorial pilot projects also shows several important issues need to be addressed for these tutorials to reach their potential. The issues that need to be addressed include tutors' commitment to carrying out their responsibilities, tutor/ student familiarization with the electronic medium, as well as the University's need to increase the availability of computers.

In summary, this study suggests that the Universitas Terbuka should continue to use Internet and Fax-Internet technologies for tutorial purposes. But the University needs to take practical steps to urge its academic staff to upgrade their skills to become more electronically wired to the global communication network. Last, but not least, Universitas Terbuka needs to collaborate with external institutions to promote the establishment of remote Internet access points, enabling the University to expand its reach and strengthen its ties with students widely dispersed throughout Indonesia.

\section{References}

Belawati, T. (1998). Mediated Counseling Services: an effort to increase student persistence in distance education. Unpublished research report. Jakarta: Universitas Terbuka.

Belawati, T. (1996). Increasing persistence in Indonesian post-secondary distance education. Unpublished Doctoral Dissertation, University of British Columbia: Canada.

Darmayanti, T. (1993). Readiness for self-directed learning and achievement of the students of Universitas Terbuka (The Indonesian Open Learning University). Unpublished Master of Arts thesis, University of Victoria: Canada.

Dunbar, R. (1991). Adapting distance education for Indonesians: Problems with learner heteronomy and a strong oral tradition. Distance Education, 12(2), 163 - 174.

Garrison, D. R. (1987). Researching dropout in distance education. Distance Education, 8(1), 95 $-101$.

Hardhono, A. P., and Belawati, T. (1998). Baseline surveys for the utilization of fax-internet technology for distance learning supports. A Proposal submitted to PanAsian R\&D Programme. Jakarta, June 1997.

Irish, G. (1978). Persistence and dropout in adult education: their relation to differential reinforcement of attendance. Unpublished doctoral dissertation. Columbia University, NY.: USA.

Kember, D. (1989). A Longitudinal-process model of drop out from distance education. Journal of Higher Education, 60(3), p. 278 - 301.

Open Learning Agency (OLA). (1991). Quick facts: Decade at a glance Brochure. Vancouver: Canada.

Roberts, D. (1984). Ways and means of reducing early student drop-out rates. Distance Education, 5(1), 50 - 71. 
Taylor, J. C. (1998). The Death of Distance: The birth of the global higher education economy. Plenary address presented and the ICDE Standing Conference of Presidents, Hyatt Coolum, Queensland, Australia, 13-16 September 1998. Retrieved January 10, 2002, from: http://www.usq.edu.au/DEC/STAFF/TAYLORJ/confer.htm.

Tinto, V. (1975). Dropout from higher education: A theoretical synthesis of recent research. Review of Educational Research, 45(1), 89 - 125.

Toha, A., Belawati, T., Hardhono, A. P., and Sigit, A. (1999). Tutorial tertulis via Internet dan Fax-Internet: Panduan operasional untuk UPBJJ (Written tutorials through Internet and Fax-Internet: Operational guidelines for regional offices). Unpublished manuscript, Universitas Terbuka. Jakarta: Indonesia.

Toha, A., Belawati, T., Hardhono, A.P., and Sigit, A. (1999). Tutorial tertulis via Internet dan Fax-Internet: Proposal uji coba (Written tutorials through Internet and Fax-Internet: Pilot Project Proposal). Unpublished manuscript, Universitas Terbuka. Jakarta: Indonesia.

University of British Columbia. (1992). UBC 1992 fact-book. Vancouver: Canada.

Universitas Terbuka. (1998). Statistik mahasiswa (Student statistics). Biro Administrasi Akademik dan Kemahasiswaan. Jakarta: Indonesia.

Universitas Terbuka. (1999a). Panduan penyelenggaraan tutorial tertulis (Guidelines for administering written tutorials through correspondence). Unpublished manuscript.

Universitas Terbuka. (1999b). Panduan penyelenggaraan tutorial radio di UPBJJ (Guidelines for administering radio tutorials in regional offices). Unpublished manuscript.

Woodley, A., and Parlett, M. (1983). Student drop-out. Teaching at a Distance, 24, 2 - 23.

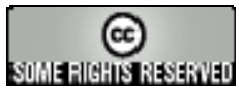

